\title{
Cystic Granular Cell Ameloblastoma
}

\author{
Rathnavel Thillaikarasi · Jayaram Balaji • Bhawna Gupta • Vadivel Ilayarja • \\ Nandimandalam Venkata Vani • Balachander Vidula • Balasubramaniam Saravanan • \\ Irulandy Ponniah
}

Received: 2 August 2009/Accepted: 3 May 2010/Published online: 27 November 2010

(C) Association of Oral and Maxillofacial Surgeons of India 2010

\begin{abstract}
Ameloblastoma is a locally aggressive benign epithelial odontogenic tumor, while unicystic ameloblastoma is a relatively less aggressive variant. Although rare in unicystic or cystic ameloblastoma, granular cell change in ameloblastoma is a recognized phenomenon. The purpose of the present article is to report a case of cystic granular cell ameloblastoma in 34-year old female.
\end{abstract}

Keywords Ameloblastoma - Granular cell · Cystic . Odontogenic

\section{Introduction}

Ameloblastoma is well recognized as a locally invasive benign neoplasm thought to arise from the cellular components of enamel organ.

As is the case with most odontogenic lesions, ameloblastoma preferentially affect the posterior mandible in middle aged adults. Ameloblastoma that manifest a multilocular radiographic pattern frequently display a honey comb or soap bubble appearance or both. Unlike the solid ameloblastoma, a less aggressive variant that tends to occur in younger individuals is the unicystic ameloblastoma

B. Gupta · V. Ilayarja · N. V. Vani · B. Vidula · I. Ponniah ( $\square)$ Department of Oral and Maxillofacial Pathology, Tamil Nadu Government Dental College and Hospital, Chennai 600 003, India

e-mail: salivaryduct@yahoo.co.uk

R. Thillaikarasi · J. Balaji · B. Saravanan

Department of Oral and Maxillofacial Surgery, Tamil Nadu

Government Dental College and Hospital, Chennai 600003 , India
[1-3]. This variant, however, is characterized by an expansile growth often with cortical perforation.

The purpose of the present article is to report a case of granular cell ameloblastoma that was grossly as well as microscopically cystic.

\section{Case Report}

A 34 years old female presented with a gradual swelling of the right side of the face of 5 years duration. Initially the swelling was painless but she described that pain developed during the last 4 months. On extra oral examination a large swelling, approximately $10 \times 8 \mathrm{~cm}^{2}$ in size, was seen extending from the angle of the mouth to the ramus of the mandible. Inferiorly, the swelling was seen to be extending approximately $2 \mathrm{~cm}$ below the lower border of the mandible (Fig. 1). The swelling was generally firm in consistency but was soft in the posterior aspect. There was no sinus or discharge. Intra orally, the swelling extended from the right mandibular first premolar to the retro molar region with obliteration of the buccal vestibule but showed no obvious expansion.

The panoramic radiograph revealed a large multilocular radiolucent lesion extending from the distal aspect of the mandibular first premolar to the ramus of the mandible involving the coronoid process but sparing the condyle (Fig. 2). Radiograph also showed expansion and thinning of coronoid process, inferior border of the mandible and the posterior border of the ramus of the mandible. In the anterior border of the ramus of the mandible the locules are smaller with altered trabecular pattern giving a honeycomb appearance. In other parts of the ramus, body and the coronoid process, the locules are larger in size with internal septations leading to a soap bubble appearance. 

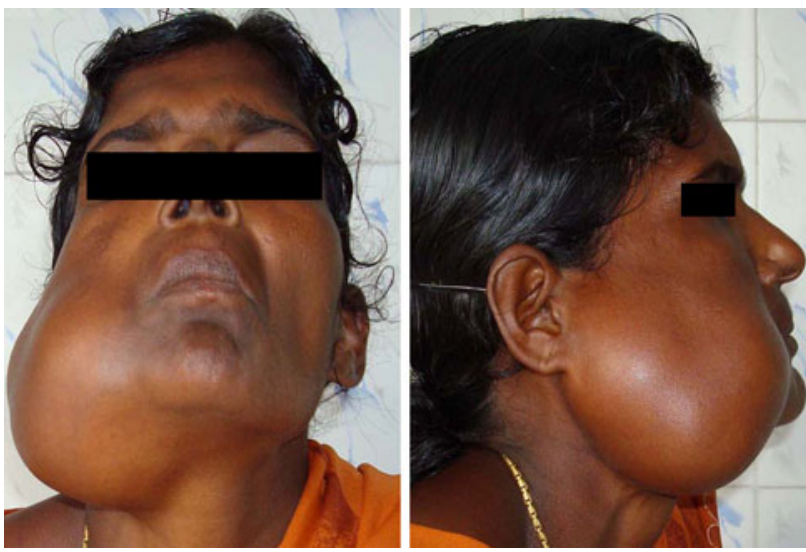

Fig. 1 The clinical appearance of the lesion

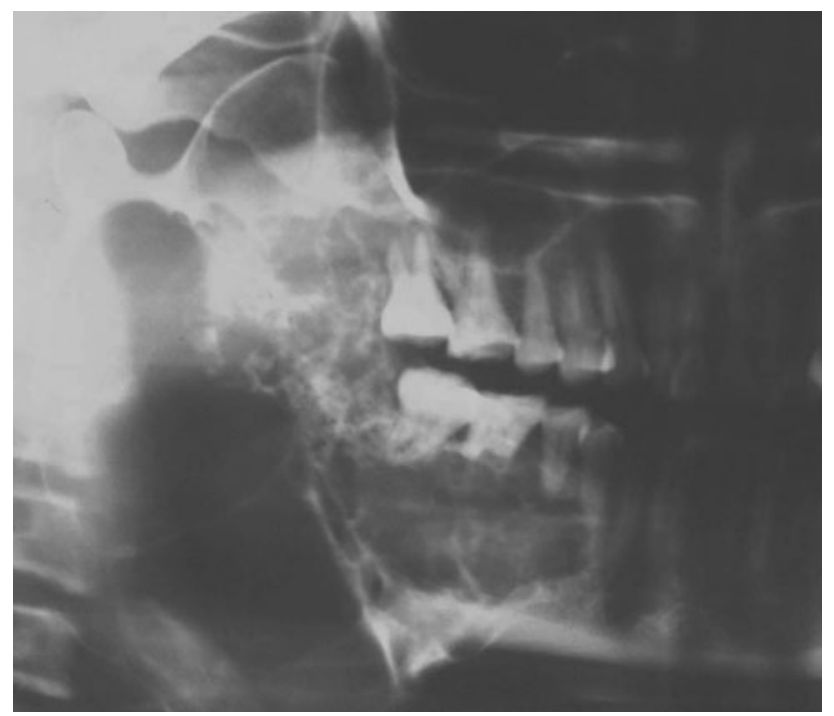

Fig. 2 Panorex shows a multilocular lesion with soap bubble and honeycomb pattern

Ameloblastoma was strongly considered as a diagnosis based on the radiographic pattern.

Under local anaesthesia, a buccal mucoperiosteal flap was reflected, and a thin film of bone over the lesion was easily removed. Soft tissue taken from the lesion showed on microscopic examination, a cystic lesion with an epithelial lining composed of peripheral basal columnar cells resembling ameloblasts and superficial granular cells with eccentrically placed round to oval nuclei supported by fibrous tissue and peripheral rim of reactive bone. A diagnosis of cystic ameloblastoma with granular cell change was rendered.

Macroscopic examination of the resected specimen revealed a large empty cystic cavity on the lingual side with internal septations at the base of the cavity. Two relatively smaller cavities were noted on the buccal aspect (Fig. 3). A greenish colored cystic fluid was noted in the

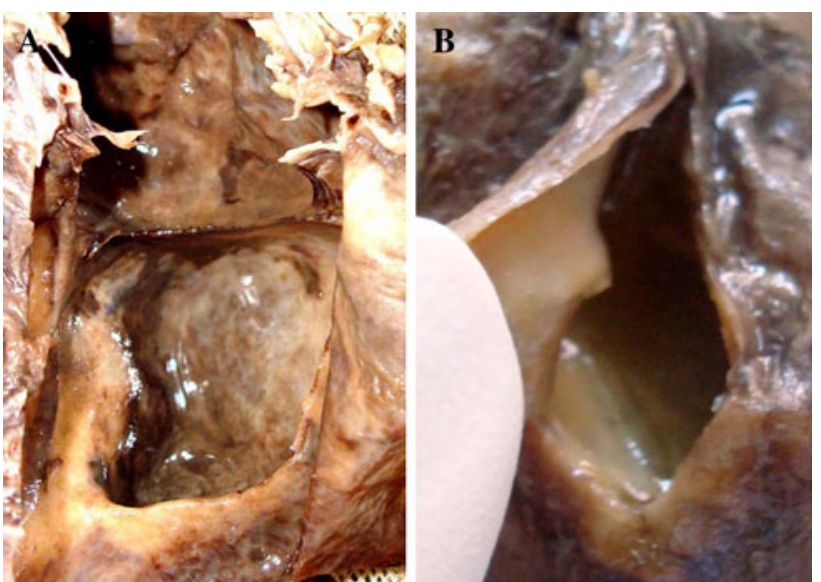

Fig. 3 (A) Empty cavity. (B) A cystic lining and cavity with green tinged fluid is evident

buccal cavities. In one of the buccal cavity, on reflection of the soft tissue covering a luminal soft tissue mass with a microcystic pattern was noted. No communication was detected between the lingual and the buccal cavities on gross examination. Representative tissue specimens were taken for histopathologic evaluation.

The specimen from the lingual side showed a thin cystic epithelial lining composed of basal columnar cells resembling ameloblasts with ball-like or focal thickening of granular cells projecting into the lumen. The epithelial lining was supported by fibrous tissue and thin peripheral reactive bone. The specimen from the buccal side showed multiple, large cystic spaces lined by peripheral ameloblast-like cells and ball-like or focal thickening of granular cells. Prominent zone of juxta epithelial hyalinization was also found (Fig. 4). Early cystic changes were observed in the ameloblastoma islands within the fibrous wall. The cystic proliferations were characteristically found between inter trabecular bone corresponding to the area between lingual and buccal cavities. Less than $15 \%$ of the lesion was composed of solid follicles with or without granular cell change. One year and eight months post surgery, no recurrence was detected on follow-up.

\section{Discussion}

It is generally interpreted that unicystic ameloblastoma is radiologically characterized as a unilocular radiolucency. While it is true that they typically present a unilocular radiolucency in a dentigerous relationship [4], the term is used to define the single cystic gross appearance $[3,5,6]$. Similarly, most clinicians regard the multicystic ameloblastoma as a multilocular radiolytic lesion when the term is actually intended to describe the gross cystic appearance of a solid ameloblastoma on surgical exploration [5, 7]. 
Fig. 4 (A) An epithelial lining composed of ameloblast-like cells and juxtaepithelial hyalinization (H\&E stain, 10X magnification). (B) Thin lining with granular cells and juxaepithelial hyalinization (H\&E stain, 20X magnification). (C) Nodular thickening composed of granular cells (H\&E stain, 40X magnification) and (D) focal thickening (H\&E stain, 5X magnification)
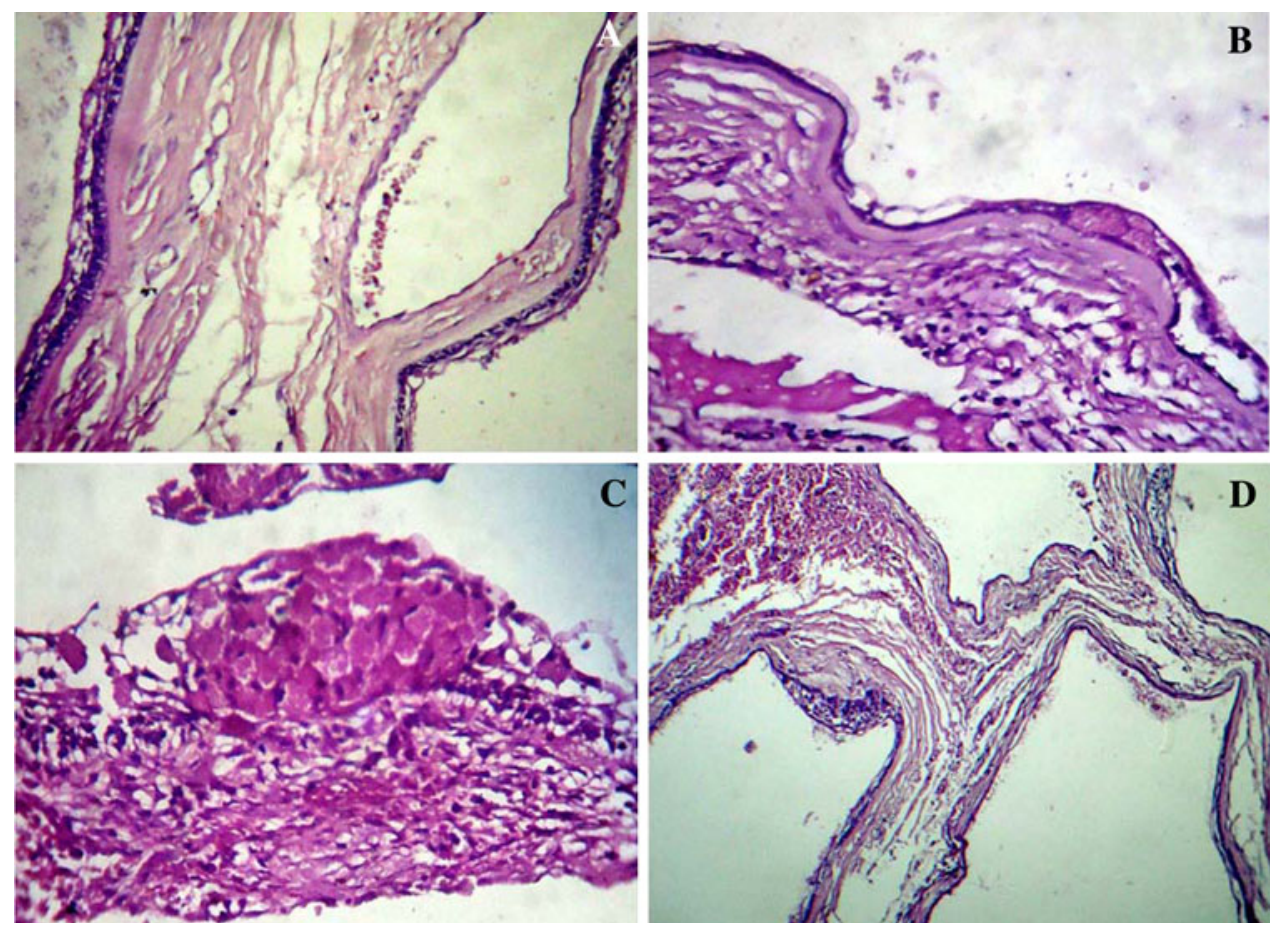

Unicystic ameloblastoma may also show a multilocular radiographic pattern, especially when it is not associated with an unerupted tooth $[3,8]$.

Recently, Rosenstein et al. [8], described a series of cystic ameloblastoma that showed more recurrence and aggressiveness as manifested by cortical perforation, large size of the lesion, multilocularity and extensive bone destruction. In the present case, the age, multilocular radiographic presentation and clinical aggressiveness correspond more closely to the description of cystic ameloblastoma reported by Rosenstein et al. [8] than that for unicystic ameloblastoma.

Although granular cell change in classic ameloblastoma is a well recognized phenomenon [9], its occurrence in the context of unicystic or cystic ameloblastoma is infrequently appreciated $[10,11]$. There has been considerable interest as to the nature of granular cells in ameloblastoma ever since it was recognized [9, 12-16]. It is evident from the literature there exist two main lines of interpretation in that some consider it a metabolic, whilst others of the view that it represent a degenerative process. More recent observation suppose the later view to be more tenable based on the increased expression of death signaling molecules in granular cells $[15,16]$.

The present case yields some interesting observation. The arrangement of granular cells in a ball-like or nodular thickening is not a feature of classic (solid) ameloblastoma that frequently show granular cell changes. The ball-like or nodular thickenings are more characteristic of odontogenic cystic lesions, especially glandular odontogenic or botryoid odontogenic cyst [17, 18]. Unicystic ameloblastoma also share this feature [6]. A zone of juxta epithelial hyalinization is typically found in unicystic ameloblastoma or calcifying odontogenic cyst but not in other cysts [6]. These observations, taken together, would indicate the possibility of de novo cystic nature of the present lesion although cystic degeneration in classic ameloblastoma is a well recognized phenomenon. However, the distinction between a de novo cystic lesion transforming into a solid tumor mass and cystic degeneration in an otherwise solid lesion cannot be established with certainty. Nevertheless, the destructive process as evident on imaging implies that it closely relates to solid ameloblastoma though it is typically microcystic on gross examination [5, 7]. From a surgical point of view the present lesion can be termed as cystic granular cell ameloblastoma as this would better reflect the difference in the age, radiographic presentation and clinical behavior of an ameloblastoma that is neither unicystic nor solid but requires measures to treat it like the latter $[5,8,19,20]$.

\section{References}

1. Robinson L, Martinez MG (1977) Unicystic ameloblastoma. A prognostically distict entity. Cancer 40(5):2278-2285

2. Gardner DG (1981) Plexiform unicystic ameloblastoma: a diagnostic problem in dentigerous cysts. Cancer 47(6):1358-1363

3. Philipsen HP, Reichart PA (1998) Unicystic ameloblastoma. A review of 193 cases from the literature. Oral Oncol 34(5):317-325

4. Kahn MA (1989) Ameloblastoma in young person: a clinicopathologic analysis and aetiologic investigation. Oral Surg Oral Med Oral Pathol 67(6):706-715 
5. Gardner DC (1996) Some current concepts on the pathology of ameloblastomas. Oral Surg Oral Med Oral Pathol Oral Radiol Endod 82(2):660-669

6. Li TJ, Wu YT, Yu SF, Yu GY (2000) Unicystic ameloblastoma. A clinicopathologic study of 33 Chinese patients. Am J Surg Pathol 24(10):1385-1392

7. Eversole LR (2001) Cystic ameloblastoma-behavior and treatment of 21 cases. J Oral Maxillofac Surg 59:1316-1318 discussion

8. Rosenstein T, Pogrel MA, Smith RA, Regezi JA (2001) Cystic ameloblastoma-behavior and treatment of 21 cases. J Oral Maxillofac Surg 59(11):1311-1316

9. Tsukada Y, Pava SG, Pickren TW (1965) Granular cell ameloblastoma with metastasis to the lungs. Report of a case and review of the literature. Cancer 18:916-925

10. Abaza NA, Gold L, Lally E (1989) Granular cell odontogenic cyst: a unicystic ameloblastoma with late recurrence as follicular ameloblastoma. J Oral Maxillofac Surg 47(2):168-175

11. Kim SG, Jung HS, Ju K (2001) A clinical, radiographic and histopathologic analysis of 71 cases. Oral Surg Oral Med Oral Pathol Oral Radiol Endod 91(6):649-653

12. Hoke HE, Harrelson AB (1967) Granular cell ameloblastoma with metastasis to the cervical vertebrae. Observations of the origin of granular cells. Cancer 20(6):991-999
13. Navarrete AR, Smith M (1971) Ultrastructure of granular cell ameloblastoma. Cancer 27(4):948-955

14. Takeda Y (1986) Intracytoplasmic crystalloids in granular cell ameloblastoma. J Oral Pathol Med 15(6):319-321

15. Kumamoto H, Ooya K (2001) Immunohistochemical and ultrastructural investigation of apoptotic cell death in granular cell ameloblastoma. J Oral Pathol Med 30(4):245-250

16. Luo HY, Yu SF, Li TJ (2006) Differential expression of apoptosis-related proteins in various cellular components of ameloblastomas. J Oral Maxillofac Surg 35(8):750-755

17. Koppang HS, Johannessen S, Haugen LK, Haares HR, Solheim T, Donath K (1998) Glandular odontogenic cyst (sialo-odontogenic cyst): report of two cases and literature review of 45 previously reported cases. J Oral Pathol Med 27(9):455-462

18. Kaplan I, Anavi Y, Manor R, Sulkes J, Calderon S (2005) The use of molecular markers as an aid in the diagnosis of glandular odontogenic cyst. Oral Oncol 41(9):895-902

19. Carlson ER, Marx RE (2006) The ameloblastoma: primary, curative surgical management. J Oral Maxillofac Surg 64(3):484-494

20. Ghandhi D, Ayoub AF, Pogrel MA, MacDonald G, Brocklebank LM, Moos KF (2006) Ameloblastoma: a surgeon's dilemma. J Oral Maxillofac Surg 64(7):1010-1014 